\title{
On modeling the variability of bedform dimensions
}

\author{
C.F. van der Mark, A. Blom \& S.J.M.H. Hulscher \\ University of Twente, Water Engineering \& Management, Enschede, The Netherlands
}

S.F. Leclair

Tulane University, Department of Earth and Environmental Sciences, New Orleans, USA

D. Mohrig

Massachusetts Institute of Technology, Dept. of Earth, Atmospheric, and Planetary Sciences, Cambridge, USA

\begin{abstract}
Bedforms are irregular features that cannot easily be described by mean values. The variations in the geometric dimensions affect the bed roughness, and they are important in the modeling of vertical sorting and in modeling the thickness of cross-strata sets. The authors analyze the variability of bedform dimensions for three sets of flume experiments, considering PDFs of bedform height, trough elevation and crest elevation divided by its mean value. It appears that the dimensionless standard deviation of the bedform height is within a narrow range for nearly all experiments. This appears to be valid for the trough elevation and crest elevation, as well. For some modeling purposes, it seems sufficient to assume that the standard deviation is a constant, so that the variation in bedform dimension can be modeled by only predicting the mean bedform dimension.
\end{abstract}

\section{INTRODUCTION}

The occurrence and development of bedforms such as river dunes or sand waves generated by water flows have been investigated extensively because of the importance of bedforms for flow resistance (e.g. Fredsøe, 1979; Van Rijn, 1984; Gabel, 1993). Bedform dimensions affect form drag and thus the total hydraulic roughness of the river or sea bed. As this hydraulic roughness influences water levels significantly, it is important to enlarge insight in the behavior of bedforms.

Several physical and empirical relationships exist that predict bedform dimensions under steady flow conditions. These relationships, based on flow and sediment properties, field and flume data, compute mean bedform characteristics. In such relationships bedforms are considered as periodic features with bedform length $\lambda$, bedform height $\Delta$ and a constant migration rate $c$. These mean bedform dimensions are generally used to predict form drag. However, bedforms are not regular. They are three-dimensional and irregular in size, shape and spacing; see, for instance, the time series of bed elevation in Figure 1.

In various situations, it appears that just applying mean values is not sufficient. Variability of bedform dimensions needs to be taken into account, for instance when modeling (1) the thickness of cross-strata sets, (2) bed roughness or (3) vertical sorting.

\subsection{Modeling the thickness of cross-strata sets}

Sets of cross-strata (also simply called cross-sets) resulting from migration of bedforms are a common sedimentary structure in sandstones of fluvial origin, see Figure 2 for an example. The thickness of crossstrata sets and bedform heights are of importance for palaeoenvironmental reconstruction. The thickness of cross-sets as seen in cross sections parallel to the mean flow direction depends among other things on the succession of bedforms of varying height or scour depth passing through the cross section and on changes in the height of individual bedforms as they migrate (Paola \& Borgman, 1991; Best \& Bridge, 1992; Bridge \& Best, 1997). This can be shown by looking at the following simple case (Paola \& Borgman, 1991). Consider a train of migrating, two-dimensional, triangular bedforms of uniform height and spacing in a situation without net aggradation. Here no stratification is formed at all, see Figure $3 a$.

A situation with bedforms of identical shape and size moving along a slowly aggrading streambed results in the formation of regular parallel crosssets with a thickness $s$ (fig. $3 b$ ). By comparing this 


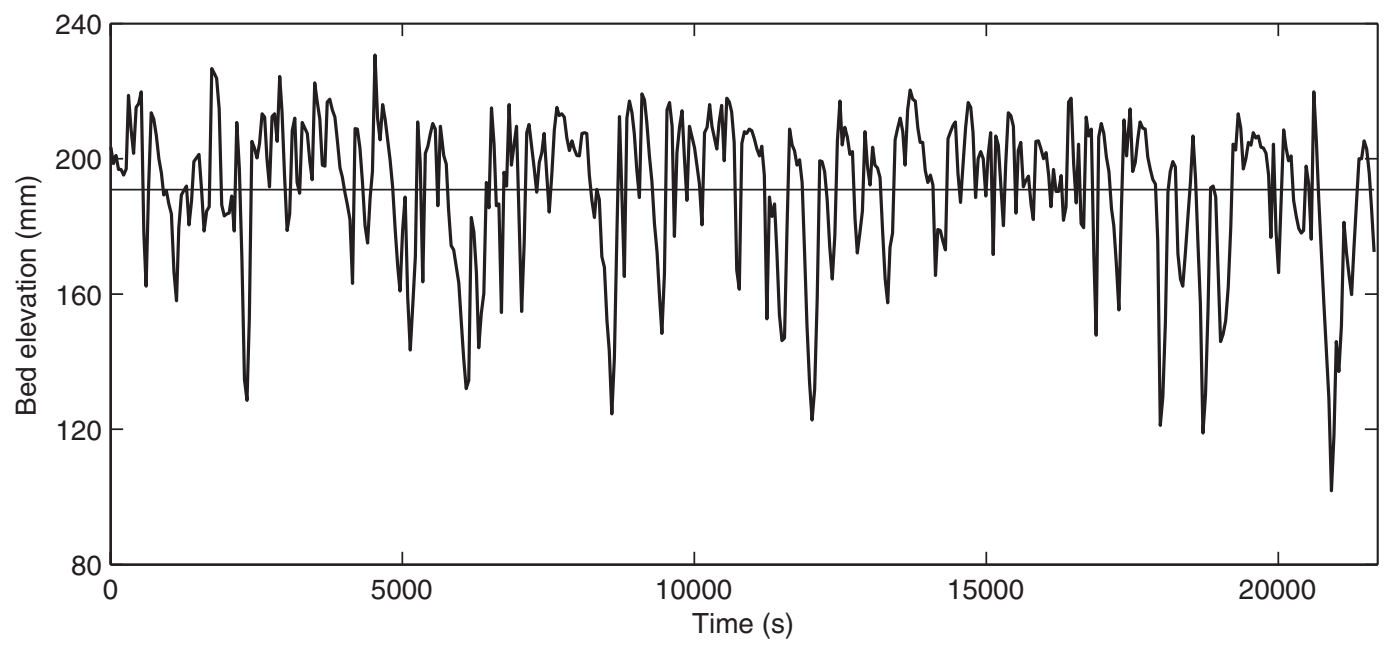

Figure 1. Time series of bed elevation at point $\mathrm{x}=800 \mathrm{~mm}$ for run BU14. Straight line is mean bed level. From Leclair (2002).

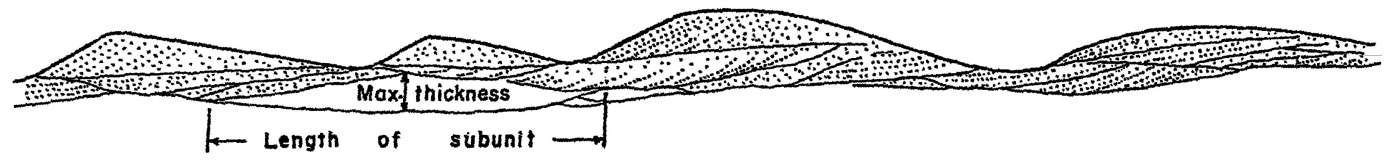

Figure 2. Cross-sets deposited by the moving bedforms of run 1 of Jopling $(1964,1965)$. The flow direction is from right to left. From Jopling (1967).

(a)

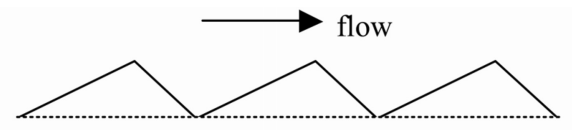

(b)

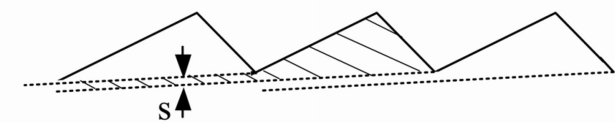

(c)

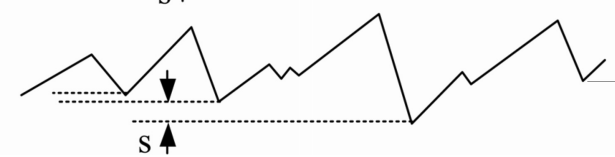

Figure 3. Sketches of triangular bedforms in cross-section, migrating from left to right. (a) Uniform bedforms, no net deposition; (b) generation of cross-sets by uniform bedforms, with net deposition; (c) irregular bedforms, no net deposition. Revised from Paola \& Borgman (1991).

perfectly regular train of bedforms with an irregular one, in the absence of net deposition (fig. 3c), it can be seen that the preserved deposit thickness is not zero for irregular bed topography (Paola \& Borgman, 1991). Only the deepest trough bedforms leave a depositional record (Best \& Bridge, 1992; Bridge \& Best, 1997), so that applying the mean value of the trough elevation will not be appropriate. Therefore in stratigraphy studies, probability density functions (PDFs) of bedform height and of bedform scour depth are introduced to be able to model the cross-set thickness. It is now possible to predict the thickness distribution of cross-sets from the bedform height distribution, and vice versa (Paola \& Borgman, 1991; Bridge \& Best, 1997).

\subsection{Modeling hydraulic roughness}

Bedforms exert a drag on the flow. On the upstream side, the rising bed elevation causes an acceleration of the flow and a decrease in pressure. Beyond the crest, water depth and pressure increase and the flow decelerates. These pressure gradients give rise to form drag. Form drag due to the presence of bedforms results in a component of flow resistance that is often called form roughness. As form roughness depends on the size, shape and spacing of the bedforms (e.g. Allen, 1983; Nelson et al., 1993), it will be clear that a field of bedforms, irregular in space and time, results in a form roughness varying in space and time, as well as the total hydraulic roughness.

\subsection{Modeling vertical sorting}

Besides the size and shape of bedforms, also vertical sorting affects the bed roughness. Vertical sediment fluxes within the bed result in a certain organization of sediment particles over depth; for instance, 
armoring of a plane river bed or downward coarsening in river dunes. This so-called vertical sorting influences the composition of the bed surface, and thus the rate and composition of the sediment transport and bedform dimensions (Blom et al., 2003). As a result, sorting affects the hydraulic roughness. Blom \& Parker (2004) have developed a new type of sediment continuity model that describes the evolution of the vertical sorting profile for a dune-covered bed. As vertical sorting and the adaptation time scale are strongly related to the variability in trough elevations, this model takes into account the irregularities in bedform size by incorporating the statistics of the trough elevations. A submodel describing (the time evolution of) the PDF of the trough elevation relative to the mean bed level is required as input to the Blom \& Parker model.

In the present research the variability in bedform height, trough elevation and crest elevation are examined by analyzing three sets of flume experiments.

\section{FLUME EXPERIMENTS}

Leclair (2002) and Blom et al. (2003) independently conducted experiments under dune conditions in sediment recirculating flumes. Leclair performed a series of runs under different flow conditions at the Binghamton University (BU), New York, USA. The present paper is based on the BU runs in which no net aggradation occurred. Blom et al.'s experiments were conducted in the Sand Flume of WL/Delft Hydraulics in the Netherlands.

Characteristics of the laboratory flumes and flow and sediment properties of the three sets of experiments (BU, T, A\&B) are listed in Table 1, wherein $L$ denotes the length of the flumes, $W$ denotes the width, $h$ the water depth, $u$ the vertically-averaged streamwise flow velocity, $D_{50}$ the median grain size, and $\Delta_{a v}$ the mean bedform height (averaged over the equilibrium period). Figure 4 shows the grain size distribution of the mixtures used in the experiments. The sediment used in set 1 was well sorted, the sediment of set 2 was poorly sorted. The sediment mixture used in the third set of experiments consisted of three well sorted size fractions with median diameters listed in Table 1. Series A and B of set 3 differed in their initial sorting profiles. The initial bed of A1 was a flat sloping bed composed of a mixture of equal proportions of the three size fractions. The initial bed of B1 consisted of a mixed layer of $3 \mathrm{~cm}$ composed of the same mixture as in $\mathrm{A} 1$, on top of a substratum composed of only the finest size fraction. Experiments A2 and B2 started from the final stages of $\mathrm{A} 1$ and $\mathrm{B} 1$, respectively.

Leclair measured bed elevations along the flume centerline in the test section, while Blom et al. measured longitudinal bed elevations at three locations
Table 1. Characteristics of experiments

\begin{tabular}{|c|c|c|c|c|c|c|c|}
\hline Set & Exp. & $\begin{array}{l}L \\
(\mathrm{~m})\end{array}$ & $\begin{array}{l}W \\
(\mathrm{~m})\end{array}$ & $\begin{array}{l}h \\
(\mathrm{~m})\end{array}$ & $\begin{array}{l}u \\
(\mathrm{~m} / \mathrm{s})\end{array}$ & $\begin{array}{l}D_{50} \\
(\mathrm{~mm})\end{array}$ & $\begin{array}{l}\Delta_{a v} \\
(\mathrm{~mm})\end{array}$ \\
\hline \multirow[t]{3}{*}{1} & BU9 & \multirow[t]{3}{*}{7.6} & \multirow[t]{3}{*}{0.6} & 0.15 & 0.5 & \multirow[t]{3}{*}{0.43} & 39.3 \\
\hline & BU14 & & & 0.15 & 0.6 & & 48.4 \\
\hline & BU21 & & & 0.15 & 0.75 & & 39.5 \\
\hline \multirow[t]{4}{*}{2} & T5 & \multirow[t]{4}{*}{50} & \multirow[t]{4}{*}{1.5} & 0.245 & 0.69 & \multirow[t]{4}{*}{1.3} & 38.5 \\
\hline & $\mathrm{T} 7$ & & & 0.354 & 0.79 & & 66.8 \\
\hline & T9 & & & 0.260 & 0.70 & & 57.8 \\
\hline & $\mathrm{T} 10$ & & & 0.193 & 0.59 & & 16.7 \\
\hline \multirow[t]{4}{*}{3} & A1 & \multirow[t]{4}{*}{50} & \multirow[t]{4}{*}{1.0} & 0.154 & 0.64 & \multirow[t]{4}{*}{ Mix* } & 22.3 \\
\hline & $\mathrm{A} 2$ & & & 0.320 & 0.83 & & 43.7 \\
\hline & B1 & & & 0.155 & 0.63 & & 25.4 \\
\hline & B2 & & & 0.389 & 0.69 & & 115.7 \\
\hline
\end{tabular}

* Mixture of three well sorted size fractions: fine $D_{50}=$ $0.68 \mathrm{~mm}$, medium $D_{50}=2.1 \mathrm{~mm}$ and coarse $D_{50}=5.7 \mathrm{~mm}$.

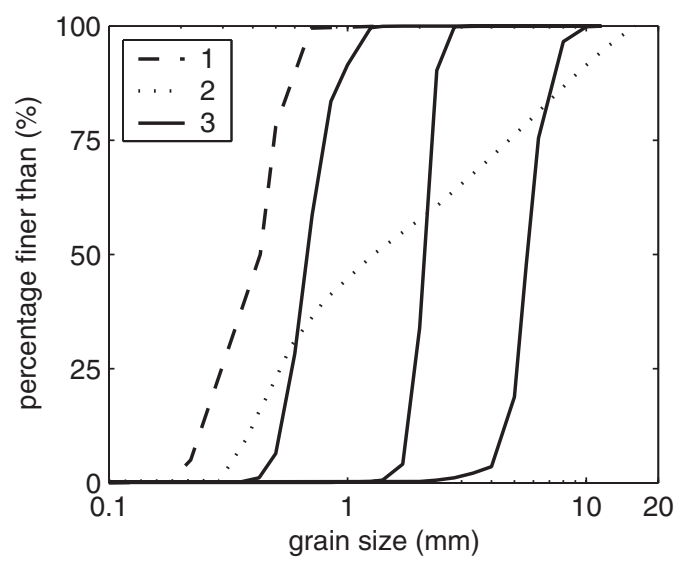

Figure 4. Grain size distributions in the experiments. The numbers refer to the numbers of the experimental sets in Table 1. From Leclair \& Blom (2005).

over the width of the flume. The measurements were taken over a region that was not influenced by the entrance and exit of the flume. All measurements were taken under equilibrium conditions, which means that bedform dimensions, flow and sediment transport rate varied around stable mean values. In the experiments discussed here, the transported sediment was recirculated and uniform flow was maintained, so that the mean bed level remained constant (no net degradation or aggradation). More detailed descriptions of the conducted experiments are given in Leclair (2002) and Blom et al. (2003). In the present research, bed elevation profiles are used to gather bedform crest and trough elevation data. Bedform height was determined from these data. 


\section{APPROACH}

For examining the variability in bedform dimensions, bedform crests and troughs are determined manually from measured bed elevation profiles. For all 11

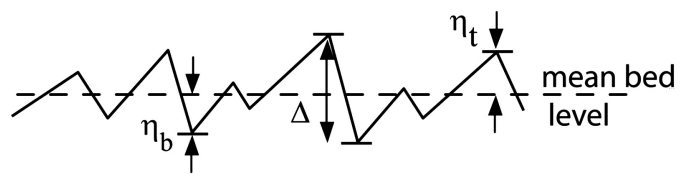

Figure 5. Definition of bedform dimensions.

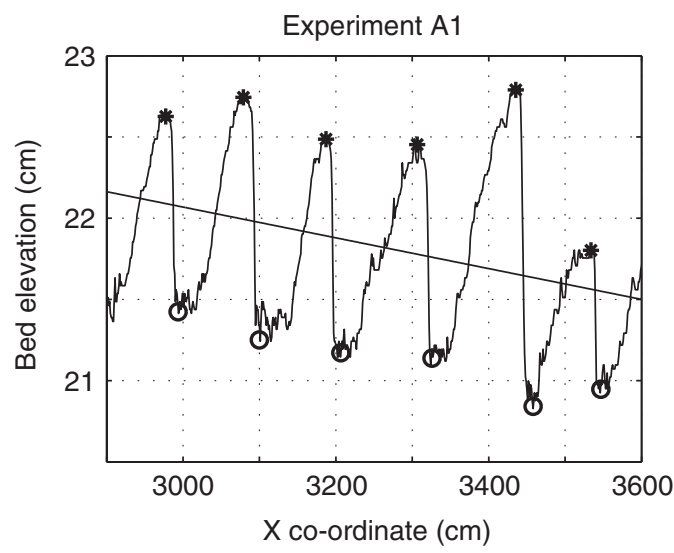

Figure 6. Example of selecting crests and troughs in a bed elevation profile. Stars indicate crests, circles indicate troughs.

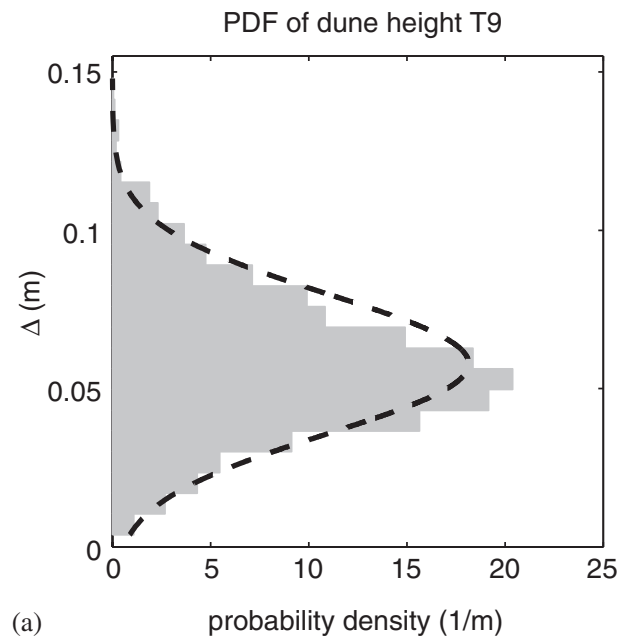

experiments this selecting of bedforms is done in the same way. Small scale bedforms (e.g. ripples migrating over dunes) are not considered. Selected bedforms are all higher than $3 \mathrm{~mm}$.

Figure 5 shows the symbols that will be used in the following. $\eta_{b}$ denotes the trough elevation relative to the mean bed level, $\Delta$ denotes bedform height and $\eta_{t}$ denotes the crest elevation relative to the mean bed level.

The bedform height is here defined as the vertical distance between a crest and its subsequent trough. Figure 6 shows how bedform crests and troughs are indicated. The amount of bed elevation profiles depends on the time between the measured bed elevation profiles and the duration of the equilibrium period.

We have plotted PDFs of bedform height, trough elevation and crest elevation of individual bedforms. For experiment T9, Figures 7, 8 and 9 show these PDFs. For the sake of comparison a best fit normal distribution is superimposed on these measured distributions of bedform height, trough elevation and crest elevation.

Figures 7a, 8a and 9a show the probability density of bedform height, trough elevation and crest elevation, respectively. Figures $7 \mathrm{~b}, 8 \mathrm{~b}$ and $9 \mathrm{~b}$ show the probability density of the dimensionless bedform height, trough elevation and crest elevation. The dimensionless random variables are found by first subtracting bedform height, trough elevation and crest elevation by their mean values, so that - by definition - the mean equals zero. Then, the random variables are made dimensionless by dividing them by their mean values. The scale on the $\mathrm{x}$-axis becomes dimensionless as well,

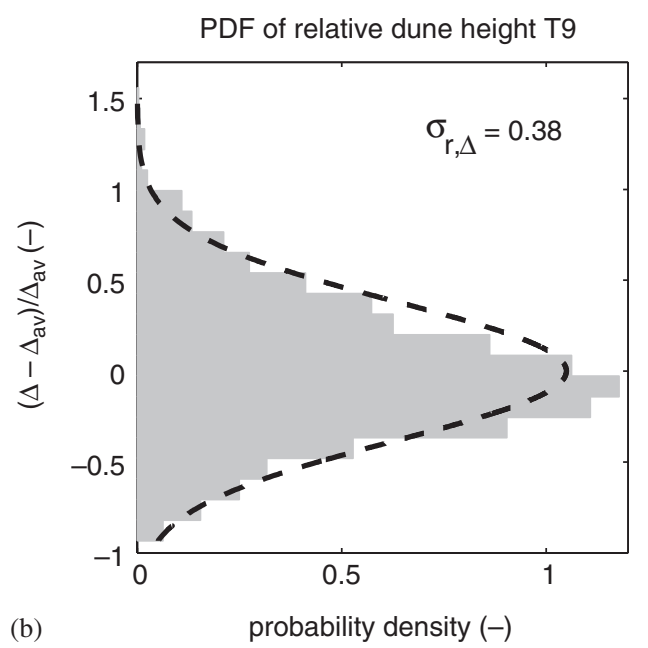

Figure 7. Stochastics of bedform height. Number of data points $N=2510$ bedform heights. (a) PDF of measured bedform height; (b) PDF of measured bedform height subtracted and divided by the mean bedform height. The dotted lines indicate the fitted Gaussian distribution with mean $\mu$ and standard deviation $\sigma$. 
as, by definition, the integral of a probability density function equals 1 .

Consider a random variable $X$ with mean $\mu$ and standard deviation $\sigma, X(\mu, \sigma)$. This random variable is subtracted by its mean and then divided by its mean, which yields the new dimensionless random variable $X^{\prime}\left(\mu^{\prime}, \sigma^{\prime}\right)$ :

$$
X^{\prime}\left(\mu^{\prime}, \sigma^{\prime}\right)=\frac{X(\mu, \sigma)-\mu}{\mu}=\frac{X^{\prime}(0, \sigma)}{\mu}=X^{\prime}(0, \sigma / \mu)
$$

It can be seen that this dimensionless random variable $X^{\prime}\left(\mu^{\prime}, \sigma^{\prime}\right)$ has a zero mean $\left(\mu^{\prime}=0\right)$ and a dimensionless standard deviation or relative standard deviation $\sigma^{\prime}=\sigma_{r}=|\sigma / \mu|$. This relative standard deviation is often called the coefficient of variance.

\section{RESULTS}

For experiment $\mathrm{T} 9$ the dimensionless standard deviation of the bedform height $\sigma_{\mathrm{r}, \Delta}$ equals 0.38 (fig. 7b). The dimensionless standard deviation of the trough elevation $\sigma_{\mathrm{r}, \eta_{\mathrm{b}}}$ and crest elevation $\sigma_{\mathrm{r}, \eta_{\mathrm{t}}}$ is found to be 0.62 and 0.50 , respectively (figs. $8 b, 9 b$ ). For the experiments listed in Table 1, the dimensionless standard deviations of bedform height, trough and
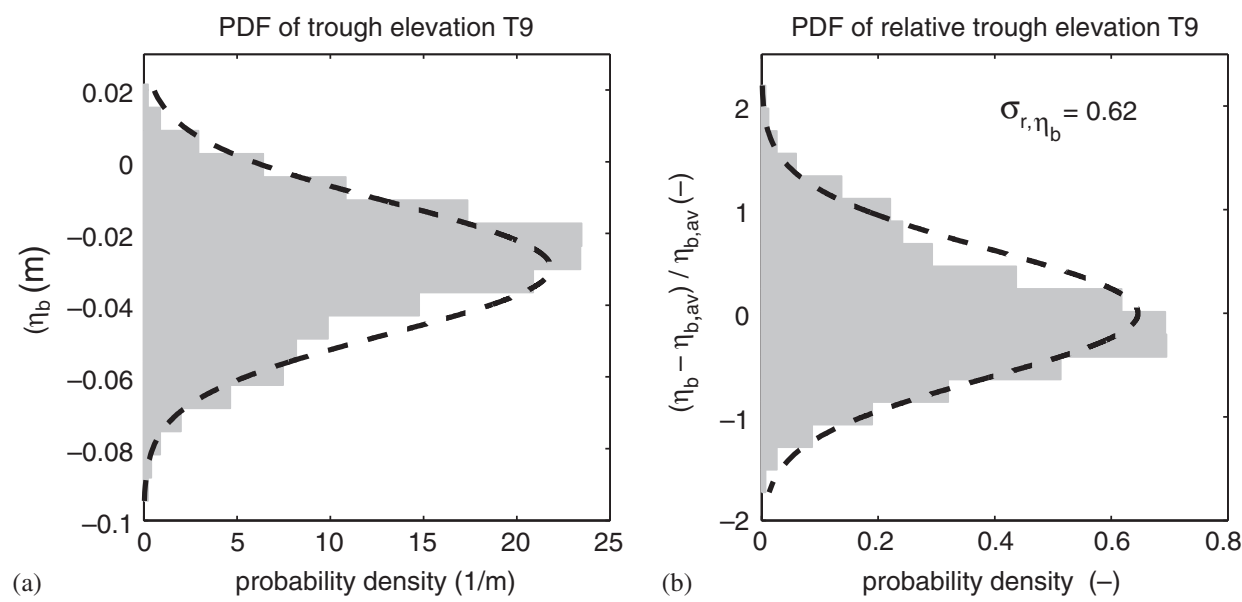

Figure 8. Stochastics of trough elevation. Number of data points $N=2633$ trough elevations. (a) PDF of measured trough elevation; (b) PDF of measured trough elevation subtracted and divided by the mean trough elevation. The dotted lines indicate the fitted Gaussian distribution with mean $\mu$ and standard deviation $\sigma$.
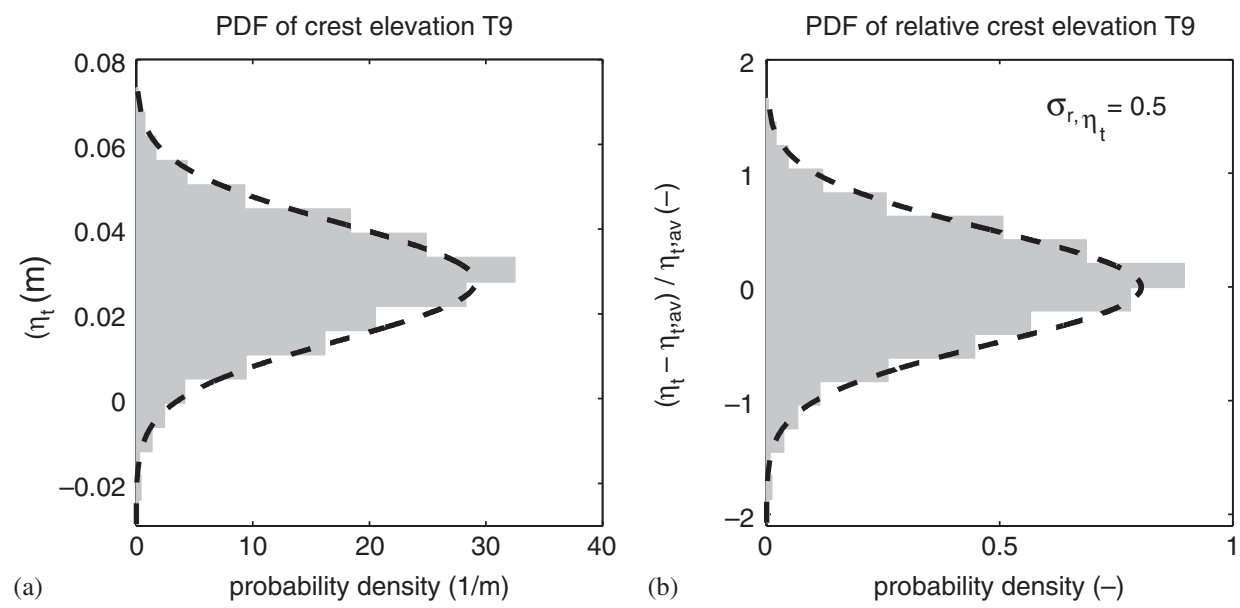

Figure 9. Stochastics of crest elevation. Number of data points $N=2619$ crest elevations. (a) PDF of measured crest elevation; (b) PDF of measured crest elevation subtracted and divided by the mean crest elevation. The dotted lines indicate the fitted Gaussian distribution with mean $\mu$ and standard deviation $\sigma$. 
Table 2. Standard deviation, mean and dimensionless standard deviation of bedform height, trough and crest elevation.

\begin{tabular}{|c|c|c|c|c|c|c|c|c|c|c|c|c|}
\hline \multirow[b]{2}{*}{ Exp. } & \multicolumn{4}{|c|}{ Bedform height } & \multicolumn{4}{|c|}{ Trough elevation } & \multicolumn{4}{|c|}{ Crest elevation } \\
\hline & $\begin{array}{l}N(-) \\
-\end{array}$ & $\begin{array}{l}\sigma \\
(\mathrm{m})\end{array}$ & $\begin{array}{l}\mu \\
(\mathrm{m})\end{array}$ & $\begin{array}{l}\sigma_{\mathrm{r}, \Delta} \\
-\end{array}$ & $\begin{array}{l}N \\
-\end{array}$ & $\begin{array}{l}\sigma \\
(\mathrm{m})\end{array}$ & $\begin{array}{l}\mu \\
(\mathrm{m})\end{array}$ & $\begin{array}{l}\sigma_{\mathrm{r}, \eta_{\mathrm{b}}} \\
-\end{array}$ & $\begin{array}{l}N \\
-\end{array}$ & $\begin{array}{l}\sigma \\
(\mathrm{m})\end{array}$ & $\begin{array}{l}\mu \\
(\mathrm{m})\end{array}$ & $\begin{array}{l}\sigma_{\mathrm{r}, \eta_{\mathrm{t}}} \\
-\end{array}$ \\
\hline BU9 & 1664 & 0.020 & 0.039 & 0.51 & 1863 & 0.020 & -0.023 & 0.87 & 1810 & 0.010 & 0.018 & 0.58 \\
\hline BU14 & 1321 & 0.027 & 0.048 & 0.57 & 1505 & 0.028 & -0.028 & 0.98 & 1458 & 0.012 & 0.020 & 0.62 \\
\hline BU21 & 1355 & 0.024 & 0.040 & 0.61 & 1565 & 0.024 & -0.023 & 1.0 & 1525 & 0.010 & 0.017 & 0.61 \\
\hline T5 & 1526 & 0.015 & 0.038 & 0.40 & 1589 & 0.012 & -0.018 & 0.65 & 1582 & 0.012 & 0.021 & 0.56 \\
\hline $\mathrm{T} 7$ & 1998 & 0.026 & 0.067 & 0.38 & 2112 & 0.022 & -0.033 & 0.67 & 2114 & 0.017 & 0.033 & 0.50 \\
\hline T9 & 2510 & 0.022 & 0.058 & 0.38 & 2633 & 0.018 & -0.030 & 0.62 & 2619 & 0.014 & 0.028 & 0.50 \\
\hline $\mathrm{T} 10$ & 1925 & 0.007 & 0.017 & 0.42 & 1979 & 0.0041 & -0.0070 & 0.59 & 1969 & 0.0058 & 0.0096 & 0.61 \\
\hline A1 & 903 & 0.0074 & 0.022 & 0.33 & 933 & 0.0041 & -0.012 & 0.34 & 934 & 0.0053 & 0.0088 & 0.60 \\
\hline $\mathrm{A} 2$ & 2488 & 0.016 & 0.044 & 0.37 & 2616 & 0.011 & -0.022 & 0.50 & 2613 & 0.013 & 0.022 & 0.60 \\
\hline $\mathrm{B} 1$ & 1201 & 0.0067 & 0.025 & 0.26 & 1244 & 0.0039 & -0.014 & 0.28 & 1235 & 0.0054 & 0.0096 & 0.56 \\
\hline B2 & 4038 & 0.035 & 0.12 & 0.30 & 4309 & 0.034 & -0.065 & 0.52 & 4301 & 0.029 & 0.051 & 0.57 \\
\hline \multicolumn{4}{|c|}{ Average of $\sigma_{\mathrm{r}}$} & 0.41 & & & & 0.64 & & & & 0.57 \\
\hline
\end{tabular}

crest elevation are shown in Table 2. $N$ denotes the number of data points.

Table 2 shows that the dimensionless standard deviation of bedform height varies around a value of 0.41 within the range $0.26-0.61$. This value was found before in other studies (e.g. Gabel, 1993; Kapitonov, 1979). The dimensionless standard deviation of trough elevation varies between 0.28 and 1.0 , with a mean value of 0.64 . The dimensionless standard deviation of crest elevation varies within a very narrow range of $0.50-0.62$, with a mean of 0.57 .

In Figure 10, the standard deviations $\sigma$ are plotted against their mean values $\mu$ for bedform height (fig. 10a), for trough elevation (fig. 10b) and for crest elevation (fig. 10c). The plotted lines have a slope that is equal to the average of the dimensionless standard deviations (Table 2).

In all three situations the standard deviation $\sigma$ increases more or less linearly with increasing mean value $\mu$. This means that the higher the bedforms are on average, the larger is the variation in bedform height. The same holds for trough elevation and crest elevation.

Although some deviations can be seen, it seems that a more or less linear relationship exists between the mean bedform height, trough elevation and crest elevation and their standard deviation. In the next paragraph these deviations will be discussed.

\section{DISCUSSION}

\subsection{Deviating data points}

In Figure 10 and Table 2, three deviations from the linear trend between $\sigma$ and $\mu$ can be distinguished: set 1 (BU-experiments) has slightly higher values for
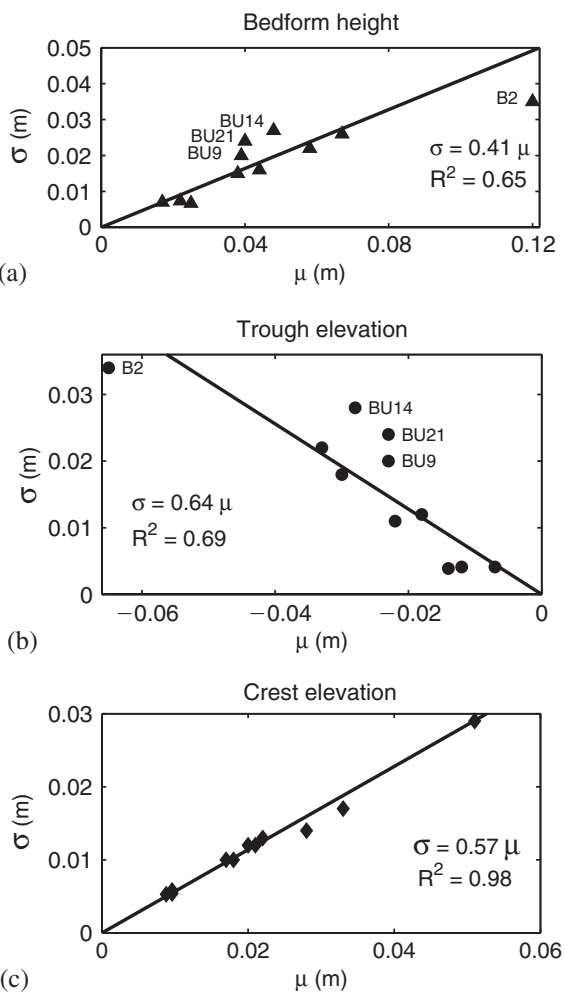

Figure 10. Standard deviation plotted against mean value for (a) bedform height; (b) trough elevation; (c) crest elevation. Lines indicate the linear relationship between standard deviation and mean. The slopes of the lines are equal to the average of the dimensionless standard deviations. $\mathrm{R}^{2}$ indicates the amount of variance from these lines. 


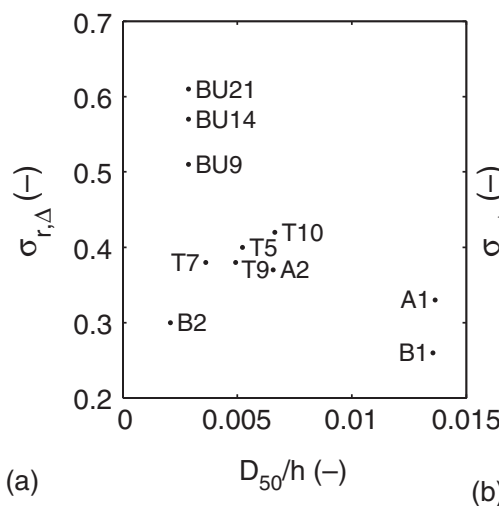

(b)

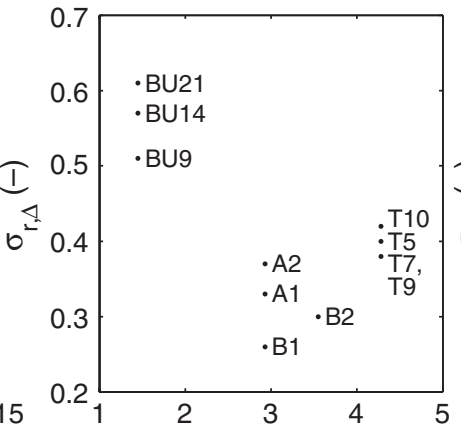

$\sigma_{g}(-)$

(c)

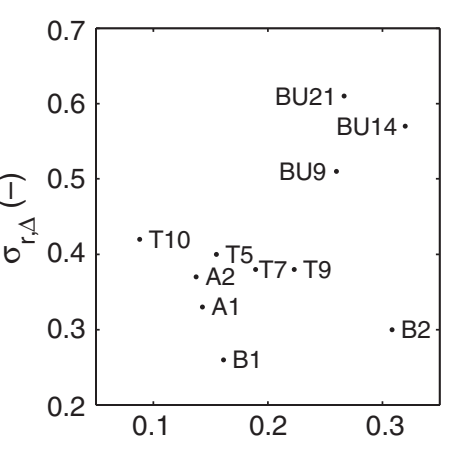

$\Delta_{\mathrm{av}} / \mathrm{h}(-)$

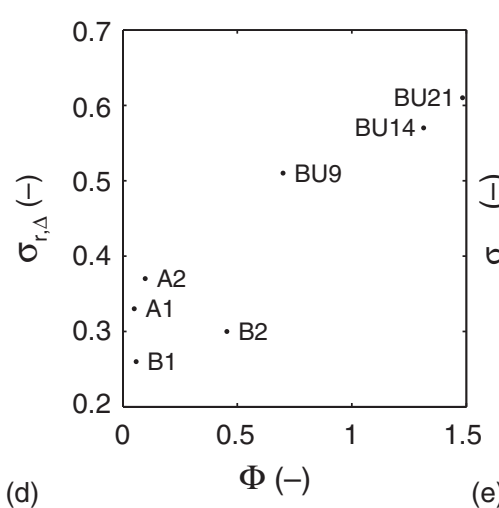

(e)

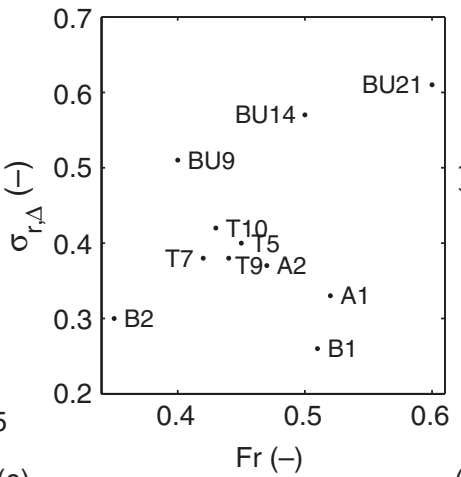

(f)

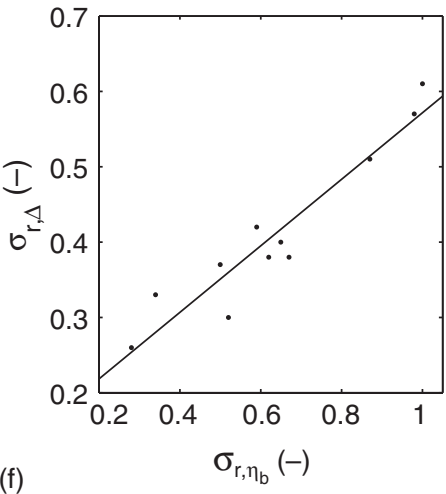

Figure 11. Comparison of experiments with respect to several physical parameters. Dimensionless standard deviation of bedform height plotted against: (a) $\mathrm{D}_{50}$ of the active bed material divided by the water depth; (b) standard deviation of the active bed material; (c) mean bedform height divided by the water depth; (d) sediment transport parameter $\Phi$; (e) Froude number; (f) standard deviation of trough elevation.

the dimensionless standard deviations than sets 2 and 3; Experiment B2 has a distinct data point for both bedform height and trough elevation in the Figures $10 \mathrm{a}$ and $10 \mathrm{~b}$, respectively; the experiments $\mathrm{A} 1$ and B1 have quite low values for the dimensionless standard deviation of both bedform height and trough elevation.

The dimensionless standard deviations of bedform height and trough elevation of set $1(\mathrm{BU})$ are significantly higher than those of set 2 and 3 . From this, we can deduce that the first set of experiments consisted of more irregular bedforms than the sets 2 and 3, which was indeed observed in the bed elevation profiles. Apparently, bedforms in experiments can differ in irregularity even if the flow properties are similar. Compare for instance experiments BU14 and A1. Although the flow characteristics are similar (Table 1), the mean bedform height and the standard deviation of bedform height vary considerably (Table 2).
It is reasonable to assume that sediment distribution influences the variability of bedforms, as this was the only physical parameter that differed significantly in both experiments. In order to find out why set 1 is more irregular, the experiments are compared with respect to sediment properties. Figure 11a shows the median grain size of the material in the active bed divided by the water depth versus the dimensionless standard deviation of bedform height. Figure $11 \mathrm{~b}$ shows the geometric standard deviation of the material in the active bed $\sigma_{g}$ versus the dimensionless standard deviation of bedform height. This geometric standard deviation gives an indication of the gradation of the sediment in the active layer and is calculated as follows:

$\sigma_{g}=0.5\left(\frac{D_{84}}{D_{50}}+\frac{D_{50}}{D_{16}}\right)$ 
Figures $11 \mathrm{a}$ and $11 \mathrm{~b}$ show that the median diameter of the sediment and the gradation are small for the BU-experiments compared to the other experiments. It seems that more widely graded sediment mixtures result in more regular bedforms than uniform sediment.

In Figure 10a, one distinct data point for bedform height can be observed, which belongs to experiment B2. In this experiment large dunes developed quickly. Compared to the other experiments, the standard deviation of bedform height and trough elevation relative to its mean value in experiment B2 is quite small (Figure 10b). It is not yet fully understood why experiment B2 had more regular bedforms than the other experiments. We sought for explanations by plotting the dimensionless standard deviation of bedform height against some physical parameters. Figure $11 \mathrm{c}$ shows $\sigma_{\mathrm{r}, \Delta}$ versus the average bedform height divided by the water depth. Figure $11 \mathrm{~d}$ shows $\sigma_{\mathrm{r}, \Delta}$ versus a sediment transport parameter $\Phi$. Only the experiments of sets 1 and 3 are plotted here, as data on bedform migration speed was not available for set 2 . The transport parameter is computed via:

$$
\Phi=\frac{q_{a}}{\sqrt{g\left(\frac{\rho_{s}-\rho}{\rho}\right) D_{50}^{3}}}
$$

Herein $\rho_{s}$ and $\rho$ denote the density of sediment and water respectively, $g$ denotes the gravitational acceleration and $q_{a}$ the sediment transport rate:

$q_{a}=c(1-p) \alpha \Delta_{a v}$

Equation 3 computes the sediment transport rate resulting from the method of dune tracking. The dune tracking method is based on the simple-wave approach; see Bagnold (1941) for more details. In equation $3, q_{\mathrm{a}}$ denotes the volume of bed load transport per unit width and time, $c$ denotes the average bedform migration speed, $p$ denotes the porosity, $\alpha$ the average bedform shape factor $\left(\alpha=-\eta_{\mathrm{b}, \mathrm{av}} / \Delta_{a v}\right)$. Figure 11e shows $\sigma_{\mathrm{r}, \Delta}$ versus the Froude number. It can be seen that the Froude number for experiment B2 is quite low, which could be a reason for the regular bedforms. However, more research is needed in order to better understand why some experiments have more regular bedforms than other experiments.

The dimensionless standard deviation of experiments A1 and B1 deviate as well. In Table 2 it can be seen that the experiments $\mathrm{A} 1$ and $\mathrm{B} 1$ have the lowest values for the dimensionless standard deviation of both bedform height (resp. 0.33 and 0.26 ) and trough elevation (resp. 0.34 and 0.28). In Blom et al. (2003) the experiments A1 and B1 are defined as Barchantype bedforms underneath which a layer of essentially immobile coarse material formed quickly. Due to the presence of this distinct coarse layer, the variability in trough elevations in A1 and B1 is small. Also Wilcock \& Southard (1989) found that the presence of a coarse bed layer underneath migrating bedforms considerably reduces the variability in trough elevations. Thus the small dimensionless standard deviations of $\mathrm{A} 1$ and $\mathrm{B} 1$ can be explained by the coarse layer underneath the bedforms, i.e. the distinct vertical sorting.

Figure 11f shows that when an experiment has regular trough elevations, also the bedform heights are regular. In other words, if an experiment has a small dimensionless standard deviation of trough elevation, the dimensionless standard deviation of bedform height will be small as well. The larger the standard deviation of trough elevation is, the larger is the standard deviation in bedform height.

From the previous, we can conclude that there exists a more or less linear relationship between $\mu$ and $\sigma$ for bedform height, trough elevation and crest elevation. However, some deviations from this linear trend are observed, which are not yet fully understood. Partly, these deviations are explained by the sediment distribution and sediment sorting. It seems however, that for some modeling purposes, it is sufficient to know that the dimensionless standard deviation varies within a certain range. However, sometimes, more detailed information is needed on the variability of bedforms. In order to be able to model the variability of bedforms in more detail, it is necessary to do more research on physical parameters that influence the behavior and thus variability of bedforms.

\subsection{Lack of clear definitions}

It is shown that the values for bedform height are determined from the manually selected troughs and crests of the bed elevation profiles. In order to compare different sets of experiments to each other correctly, it is necessary to treat them in the same way. Although it seems obvious to use the same definitions for determining bedform heights or lengths from measured data, in literature several methods are applied to define bedform height and length. Schilperoort (1984) summarizes what kind of problems has to be dealt with in defining bedform dimensions:

- Some researchers take into account smaller-scale bedforms, some don't;

- The question arises whether bedforms with characteristics less than a specific threshold value should be excluded from the analysis. For instance Allen (1984) defines dunes as bedforms longer than $600 \mathrm{~mm}$ and higher than $40 \mathrm{~mm}$. The introduction of such threshold values can influence the histograms and the fitted PDFs considerably.

- Bedform length can be defined as the horizontal distance between two successive mean bed level upcrossings. A mean bed level upcrossing is here 
defined as the point where the upward going bed elevation profile crosses the mean bed level. Here again it is questionable if all mean bed level upcrossings of the bed elevation should be treated as demarcating individual bedforms or if some bedforms should be excluded. Bedform length can also be defined as the horizontal distance between two successive mean bed level downcrossings or between two successive troughs or between two successive crests.

- Likewise bedform height can be defined as the vertical distance between a crest and the subsequent trough or between a trough and its subsequent crest.

The choice for a definition is usually made subjectively. This lack of a clear geometric definition may have its consequences when measured dimensions are interpreted. It is generally difficult to make a comparison between bedform data of different researchers, if the original bed elevation profiles are lacking. This definition problem, together with the problem of not having a sufficient number of bedform units (especially in cases of short distance series), may lead to an unreliable comparison between the empirical histogram and the fitted probability density function.

In this research all crests and troughs are selected by hand, so that smaller scale bedforms could be excluded from the datasets. It will be evident that this is not an adequate method to select bedforms, as subjectivity cannot be avoided.

Consider for instance Figure 12. Bedforms 1 and 2 were defined as bedforms likely to include in the bedform data-set, although it may be debatable excluding bedform 2 from the data-set. In contrast to the irregular experiments of set 1 , in the more regular experiments of sets 2 and 3 the selecting of bedforms was less doubtful (Figure 6 will not lead to discussion). A threshold or definition that distinguishes between bedforms that are included and excluded is desirable and necessary. Including small bedforms like bedform 2 results in a larger variation in bedform height and thus a larger standard deviation.

The type of probability distribution also appears to differ per experiment. For instance, the bedform height in experiment $\mathrm{T} 9$ could be described by a normal distribution or even better a Gamma distribution (fig. 7a). Ashida \& Tanaka (1967) concluded from their experiments that in a dune regime their bedform heights (which were not clearly defined) follow approximately a Rayleigh distribution. Nordin (1971) found the dune height (defined as vertical distance between trough and subsequent crest) to approach the Rayleigh distribution. Wang \& Shen (1980) found the Weibull distribution to be the best fit for their dune height data with a shape parameter B ranging between 2 and 2.6. Annambhotla et al. (1972) found an exponential distribution for their river bedform heights. The question arises whether these different distributions are
Experiment BU21, bed elevation profile 100
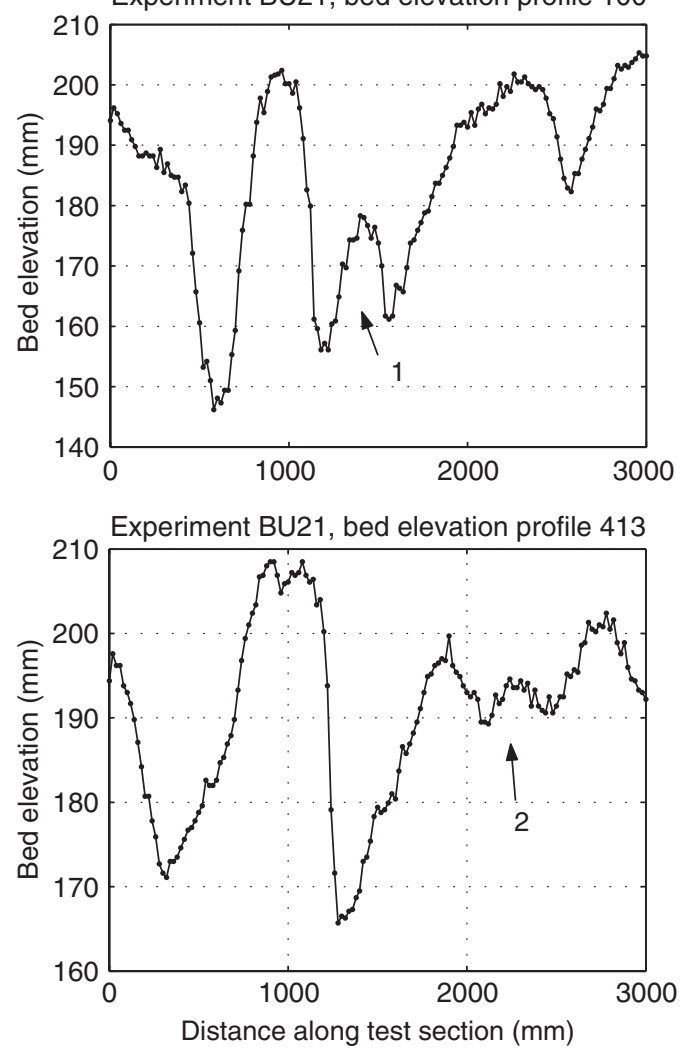

Figure 12. Two bed elevation profiles of experiment BU21. The flow direction is from left to right.

related to applying a different definition of bedform dimensions.

In order to characterize bedform dimensions stochastically, it is beyond doubt that the definition of bedform dimensions and the amount of bedform units are relevant elements. Consensus about the best way to define bedform dimensions is therefore desirable.

\subsection{Consequences for morphodynamic modeling}

A dimensionless standard deviation of bedform height, trough elevation or crest elevation that appears to be within a narrow range or is even a constant value is worthwhile in any model that takes into account bedforms. In case of a constant dimensionless standard deviation, the variation in bedform height can be modeled by only predicting the mean bedform height. The same holds for trough elevation and crest elevation.

This could be very useful in for instance the case of computing the effect of sorting using the sediment continuity model developed by Blom \& Parker (2004). For computing the time evolution of a sorting profile, 
it is necessary to have a submodel for the time evolution of the PDF of trough elevations. By assuming the dimensionless standard deviation to be a constant, only the time evolution of the mean trough elevation has to be modeled. For this purpose, an existing dune height model can be used.

The objectives of a research determine how accurate the results of a model should be. For some modeling purposes, assuming that the dimensionless standard deviation is a constant will give adequate modeling results; in other cases the results will not be accurate enough. It is not yet clear in what situations applying a linear relationship between $\mu$ and $\sigma$ is sufficient. In the case of modeling stratigraphy, it is clear that using a constant value would not be appropriate, as here the extreme values of trough elevation are of relevance. Probably, assuming a linear relationship will also give inaccurate results in the case of well sorted sediment.

For all modeling purposes, a clear definition of bedform height is needed. Applying another definition for bedform height will lead to another mean value and to another standard deviation. Therefore, it is recommended to consider and discuss what the best definition is.

\section{CONCLUSIONS}

The stochastics of bedform dimensions are investigated for three sets of flume experiments. The three random variables bedform height, trough elevation relative to mean bed level and crest elevation relative to mean bed level are considered. It appears that the standard deviation $\sigma$ increases more or less linearly with increasing mean value $\mu$. This results in a dimensionless standard deviation $\sigma / \mu$ that is within a narrow range. The dimensionless standard deviation of bedform height varies around 0.4 and of trough elevation and crest elevation around 0.6.

Deviations from these constants can be seen; these seem to originate from the sediment distribution and sediment sorting (for instance a coarse layer underneath the migrating bedforms).

For some modeling purposes it seems sufficient to apply a constant value for the dimensionless standard deviation. The variation in bedform height can then be modeled by only predicting the mean bedform height. The same holds for trough elevation and crest elevation.

However, in other cases more detailed information may be needed about the variability in bedform dimensions. In this situation, one would like to use an improved model. More research is needed to better understand variations in bedform dimensions, and the physical parameters that determine the behavior and variability of bedforms. In future research the authors will investigate which parameters affect the variability in bedforms. Furthermore we will include more (field) experiments in this research, in order to better understand and thus model the variability in bedforms. We also would like to investigate whether this analysis is useful for sand waves in a marine environment.

This paper is also intended to encourage researchers to consider how bedforms are best defined, so that in future research the same definition will be applied.

\section{ACKNOWLEDGEMENTS}

This research, which is part of the project ROUGH WATER (project number TCB.6231), is supported by the Technology Foundation (STW) of the Netherlands organization of scientific research (NWO). The authors would like to acknowledge the National Center for Earth-surface Dynamics (NCED) for supporting the joint research between the University of Twente, MIT and the University of Minnesota.

\section{REFERENCES}

Allen, J. R. L. (1983). River bedforms: progress and problems. In: Modern and ancient fluvial systems, Collinson, J. D. and Lewin, J. (eds.), vol. 6, pp. 19-33, Int. Assoc. Sedimentol. Spec. Publ., Blackwell, Boston.

Allen, J. R. L. (1984). Sedimentary structures: Their character and physical basis. Elsevier, Amsterdam, $631 \mathrm{pp}$.

Annambhotla, V. S. S., Sayre, W. W., \& Livesey, R. H. (1972). Statistical properties of Missouri River bedforms. Journal of Waterways, Harbors Coastal Eng. Div. ASCE, 98 (WW4), pp. 489-510.

Ashida, K. \& Tanaka, Y. (1967). A statistical study of sand waves. In: Proceedings of the 12th IAHR congress, pp. 103-110, Fort Collins, Colorado.

Bagnold, R. A. (1941). The Physics of Blown Sand and Desert Dunes, Methuen, London.

Best, J. L. \& Bridge, J. S. (1992). The morphology and dynamics of low amplitude bed waves upon upper stage plane beds and the preservation of planar laminae. Sedimentology, 39, pp. 737-752.

Blom, A. \& Parker, G. (2004). Vertical sorting and the morphodynamics of bed form-dominated rivers: A modeling framework. Journal of Geophysical Research, 109 (F02007), pp. 1-15.

Blom, A., Ribberink, J. S., \& De Vriend, H. J. (2003). Vertical sorting in bed forms: Flume experiments with a natural and a trimodal sediment mixture. Water Resources Research, 39 (2).

Bridge, J. S. \& Best, J. L. (1997). Preservation of planar laminae due to migration of low-relief bed waves over aggrading upper-stage plane beds: Comparison of experimental data with theory. Sedimentology, 44 (3), pp. 253-262.

Fredsøe, J. (1979). Unsteady flow in straight alluvial streams: modification of individual dunes, J. Fluid Mech., 91 (3), pp. 497-512.

Gabel, S. L. (1993). Geometry and kinematics of dunes during steady and unsteady flows in the Calamus River, Nebraska, USA. Sedimentology, 40, pp. 237-269. 
Jopling, A. V. (1964). Laboratory study of sorting processes related to flow separation. Journal of Geophysical Research, 69, pp. 3403-3418.

Jopling, A. V. (1965). Laboratory study of the distribution of grain sizes in cross-bedded deposits. In: Primary sedimentary structures and their hydrodynamic interpretation, Middleton, G. (ed.), vol. 12, pp. 53-65, Soc. Econ. Paleontologists and Mineralogists, Spec. Publ.

Jopling, A. V. (1967). Origin of laminae deposited by the movement of ripples along a streambed: a laboratory study. Journal of Geology, 75, pp. 287-305.

Kapitonov, N. M. (1979). Distribution function of the characteristics of bottom ridges according to measurements in the Don River. Sov. Hydrol., 18, pp. 292-295.

Leclair, S. F. \& Blom, A. (2005). A qualitative analysis of the distribution of bed-surface elevation and the characteristics of associated deposits for subaqueous dunes. Special Publications of the International Association of Sedimentology, 35, pp. 121-134.

Leclair, S. F. (2002). Preservation of cross-strata due to the migration of subaqueous dunes: an experimental investigation. Sedimentology, 49, pp. 1157-1180.

Nelson, J. M., McLean, S. R., \& Wolfe, S. R. (1993). Mean flow and turbulence fields over 2-dimensional bed forms. Water Resources Research, 29 (12), pp. 3935-3953.
Nordin Jr, C. F. (1971). Statistical properties of dune profiles. Sediment transport in alluvial channels. Geological Survey Professional paper, 562-F. US government Printing Office, Washington, 41p.

Paola, C. \& Borgman, L. (1991). Reconstructing random topography from preserved stratification. Sedimentology, 38 , pp. 553-565.

Schilperoort, T. (1984). A critical review of literature on the stochastic analysis of bedform dimensions - Report on investigation. TOW report R657-XIV/M1314 part VII, Delft hydraulics laboratory.

Van Rijn, L. C. (1984). Sediment transport, part III: Bed forms and alluvial roughness. Journal of Hydraulic Engineering, 110 (12), pp. 1733-1754.

Wang, W. C. \& Shen, H. W. (1980). Statistical properties of alluvial bed forms. In: Proceedings 3rd International Symposium on Stochastic Hydraulics, pp. 371-389, Tokyo, Japan.

Wilcock, P. R. \& Southard, J. B. (1989). Bed load transport of mixed size sediment: fractional transport rates, bed forms, and the development of a coarse bed surface layer. Water Resources Research, 25 (7), pp. 1629-1641. 
